\title{
GIS-based study on the Bohai Strait cross-sea channel route scheme
}

\author{
Yu Li ${ }^{1, a}$, Xiaodan $\mathrm{Ha}^{2, b}$ \\ ${ }^{1}$ Mailbox 350,Dalian Jiaotong University, No.794 Huanghe Road, ShaHeKou District, Dalian, \\ Liaoning Province, China \\ ${ }^{2}$ room403,building B No.1,No.37,Jixianbei Street, ShaHeKou District, Dalian, Liaoning Province, \\ China \\ a467797823@qq.com, b1113659968@qq.com
}

Keywords: tunnel engineering; line scheme; GIS; the Bohai Strait; cross-sea channel

Abstract: The Bohai Strait cross-sea channel, an undersea tunnel, is proposed to connect Dalian, Liaoning province and Penglai, Shandong province. The construction of the Bohai Strait cross-sea channel project can restrict the important project of national development from a certain angle, and it is helpful to promote the economic integration development of Circum-Bohai region, which has a certain importance and necessity. In order to explore the route choice of the Bohai Strait cross-sea channel, based on the theory of basic geographic information system, this paper gets data from the computer network information center China International Academy of scientific data and to obtain the contour map of the mirror site construction projects within the region by using Arc GIS software applications. According to the importance of the influence of the Bohai Strait cross-sea channel route to society and country, to explore the concrete scheme of the Bohai Strait cross-sea channel of line selection, the contour map is imported into the Auto CAD software and the specific scheme is designed. In this paper, four different route schemes are proposed, which provide a reference for the construction of the Bohai Strait cross-sea channel project. Meanwhile, this paper also compares the selection of other experts for the comparison of multiple schemes, which is based on the length of the route and the number of islands. It can provide reference for the construction of the Bohai Strait cross-sea channel.

\section{Introduction}

Since ancient times, the Bohai Strait is the China's second largest strait. The Liaodong Peninsula and the Shandong Peninsula were across the Bohai Strait, and the Bohai Strait is also an important channel connecting Bohai and the Yellow Sea. At the same time, the Bohai Strait is also our country's political, economic and Cultural Center which is of strategic importance to Beijing, Tianjin and Hebei region. It is of great strategic significance to protect China's sovereignty and territorial integrity. In view of the Bohai Strait as a barrier between the Yellow Sea and Bohai, communication between cities in the Circum-Bohai region has been a problem for people. While Shanhaiguan is the only land connection in many places, and the transport situation has been in a state of tension.

Yueling Zhang [1] pointed out that the Bohai Strait cross-sea channel construction scheme selection, project scheme selection, the landing position selection scheme, the plane position selection scheme, selecting the construction plan of the project. Bing Wang, Changning Deng and

Fei Liu [2] pointed out that because of the high cost and high risk, almost no one use air transport to carry out the transport of goods. The use of the existing ordinary railway, high-speed railway and 
highway were mostly above $90 \%$. Mengshu Wang [3,4] pointed out that the Bohai Strait cross-sea channel recommended to Lvshun and Penglai island line scheme is better. Cross-sea channel uses the whole railway tunnel project and the car can be carried through the shuttle train through the tunnel. Yuwu Sun [5], Kezhi Song and others [6,7] study listed the Bohai Strait cross-sea channel project construction importance, necessity, feasibility and advantages, which laid the foundation for subsequent channel construction. Among them, Kezhi Song and Mengshu Wang, who has also developed a natural and geological condition of the project, the construction scheme, selection and construction methods for the construction of the channel provide a reference. In foreign countries, the existing British and French submarine tunnel, Japan's Seikan tunnel, Japan Tokyo Bay Subsea Tunnel [8] and many other successful project cases are for our learning, reference, study. Therefore, the construction of the Bohai Strait cross-sea channel should be conducted. This is bound to make the traffic situation in the Circum-Bohai region to be changed, prompting the economic development of Circum-Bohai region and other regions around the world, and enhancing China's comprehensive national strength.

This paper uses theoretical knowledge of the geographic information system; Arc GIS software based on the construction of engineering within generated contour maps, and imports it to Auto CAD basis for subsequent selection. Based on the contour map and code for design of High Speed Railway [9] design requirements, integrated nature conditions, engineering geology, climate, hydrology, natural disasters, national defense and war defense, environment, navigation at sea and varieties of factors of the Bohai Strait cross-sea channel, this paper designs four route schemes.

\section{Natural background of route selection}

The shortest distance between the north and south ends of the Bohai Strait is about 109 kilometers, the width is about 106 kilometers, and the average water depth is 25 meters. The northern part of the Bohai Strait_ - the LaoTieShan channel width is about 42 kilometers, accounted for the entire channel $40 \%$, above the average water depth is 40 meters, and the largest depth is about 83 meters. North and south to a total of 32 islands, of which there are larger Beihuangcheng Island, Daqin Island, Tuoji Island, Gaoshan Island, Daheishan Island, Beichangshan Island and Nanchangshan island etc.. There are 66 uncovered reefs, 16 hidden reefs, and 2 long beaches (the depth of 1.6 4 meters). The Bohai Strait is third Department of Geology and Quaternary strata of Cenozoic, and the project area approaches the Zhangjiakou-Penglai fault belt and the Tanlu fault belt. Therefore, it may encounter some natural disasters, such as earthquakes. Climatic conditions in project area of the Bohai Strait cross-sea channel are good and it also has good hydrological conditions. The southern Bohai Strait Miao islands of Miaodao islands have eelgrass ecosystem, Miaodao archipelago plantation ecosystem, south five islands of Miaodao archipelago ecosystems, Miaodao islands, north island ecosystem, Miaodao islands wetland ecosystem and other ecosystems.

\section{Cross-sea channel route selection based on GIS}

\section{The theoretical basis of the GIS}

The full name of GIS is Geographic Information System, meaning geographic information system [10], and it is a very important spatial information system. GIS is the use of computer hardware and software systems to support the whole or part of the earth's geographic distribution data collection, storage, management, operation, analysis, display and description. The data source of GIS is the position of the point, which may be marked by longitude, latitude and elevation coordinates, or by other geocoding systems. The GIS system can convert the digital information that is not a map form 
to the form of identification. Then, we can use ArcGIS software Arc Map for data reading, analysis, processing, and then get the results we need.

\section{Generation of DEM data from contour routes}

First of all, it downloaded from China Academy of Sciences Computer Network Information Center, the international scientific data mirror website_—www.gscloud.cn database SRTMDEM 90M original resolution elevation data of the Bohai Strait cross-sea channel route range by strm_61_05.img remote sensing satellite image generation. Its center longitude is 122.5, the central latitude is 37.5, and every one of 5 degrees of a cell. Then, satellite image of the satellite will deal with geographic processing in Arc GIS software Arc Map. The contour map of the area is generated by using the function of ArcToolbox Tools, which is based on the function of selecting 3DAnalyst $50 \mathrm{~mm}$ - grid surface - isocline. The resulting contour map is exported to the AutoCAD image; the follow-up can be carried out in the AutoCAD software route selection. The contour map of the entire download area is shown in Fig.1, and an enlarged contour map of the project area is shown in Fig.2.

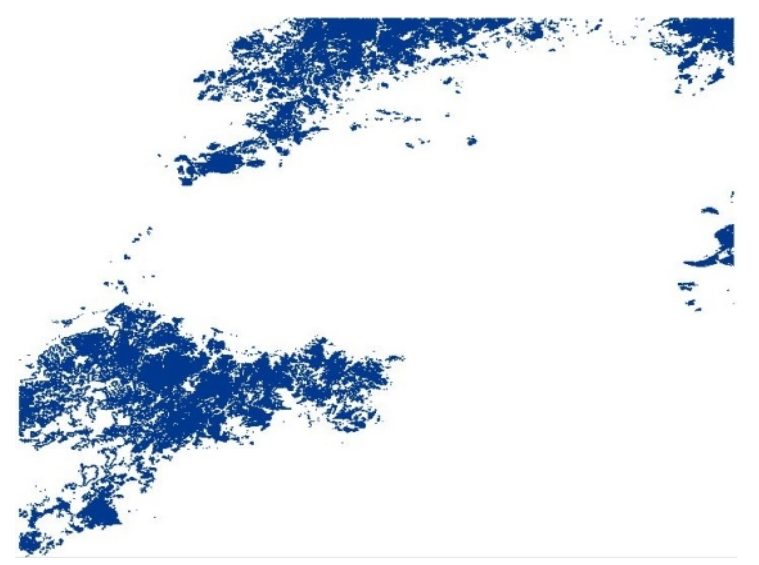

Fig. 1 Contour map a

\section{Route selection}



Fig. 2 Contour map b

(1) Scheme one

The starting point QD is in the southwest corner of the LaoTieShan, and the landing point ZD is in the port of Penglai, whose route goes through Beihuangcheng Island, Nanhuangcheng Island, Tuoji Island, Beichangshan Island and Nanchangshan Island. Developed the first line length is 81.10 kilometers, refer to the "code for design of High Speed Railway" [9], it can be concluded that the easement curve is 240 meters. Circle curve radius is 7000 meters corresponding to the angle of 
radians $\frac{19 \pi}{45}$. The last line is 21.15 kilometers. The total length of the route is 112020 meters, or 112.02 kilometers. The schematic diagram of the scheme one is shown in Fig.3.

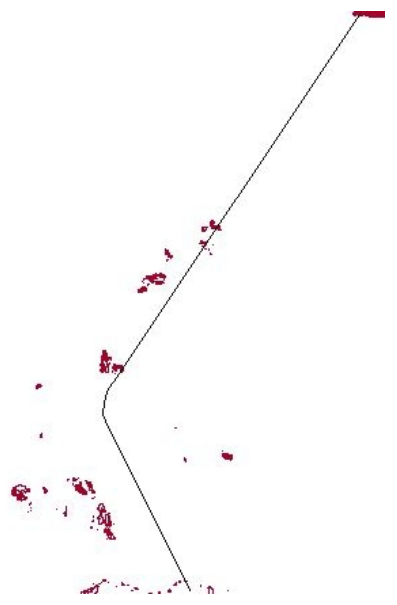

Fig.3 Cross-sea channel route selection scheme one

(2) Scheme two

The starting point QD is in the southwest corner of the LaoTieShan, and the landing point ZD is in the port of Penglai, whose route goes through Beihuangcheng Island, Nanhuangcheng Island and Tuoji Island. Developed the first line length is 70.05 kilometers, refer to the "code for design of High Speed Railway" [9], it can be concluded that the easement curve is 280 meters. Circle curve radius is 6000 meters corresponding to the angle of radians $\frac{61 \pi}{180}$. The last line is 37.40 kilometers. The total length of the route is 114370 meters, or 113.37 kilometers. The schematic diagram of scheme two is shown in Fig.4.



Fig.4 Cross-sea channel route selection scheme two

(3) Scheme three

The starting point QD is in the southwest corner of the LaoTieShan, and the landing point ZD is in the port of Penglai, whose route goes through Beihuangcheng Island, Nanhuangcheng Island, Tuoji Island, Nanchangshan Island and Miao Island. Developed the first line length is 84.29 kilometers, refer to the "code for design of High Speed Railway" [9], it can be concluded that the easement curve is 340 meters. Circle curve radius is 5000 meters corresponding to the angle of radians $\frac{21 \pi}{45}$. The last line is 25.17 kilometers. The total length of the route is 117440 meters, or 
117.44 kilometers. The schematic diagram of scheme three is shown in Fig.5.

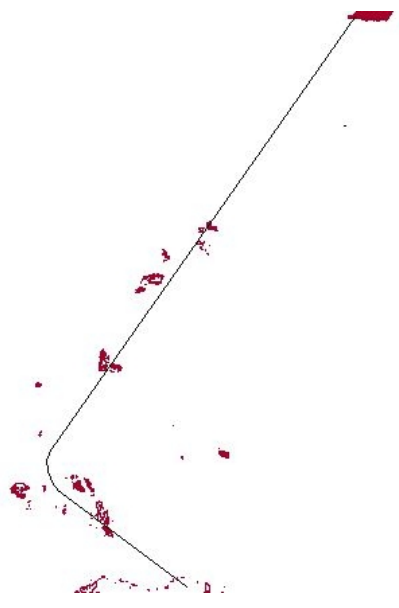

Fig.5 Cross-sea channel route selection scheme three

(4) Scheme four

The starting point QD is in the southwest corner of the LaoTieShan, and the landing point ZD is in the port of Penglai, whose route goes through Xiaoqin Island, Daqin Island, Daheishan Island, Miao Island and Nanchangshan Island. Developed the first line length is 87.65 kilometers, refer to the "code for design of High Speed Railway" [9], it can be concluded that the easement curve is 380 meters. Circle curve radius is 4500 meters corresponding to the angle of radians $\frac{19 \pi}{36}$. The last line is 29.83 kilometers. The total length of the route is 125960 meters, or 125.69 kilometers. The schematic diagram of the scheme four is in Fig.6.

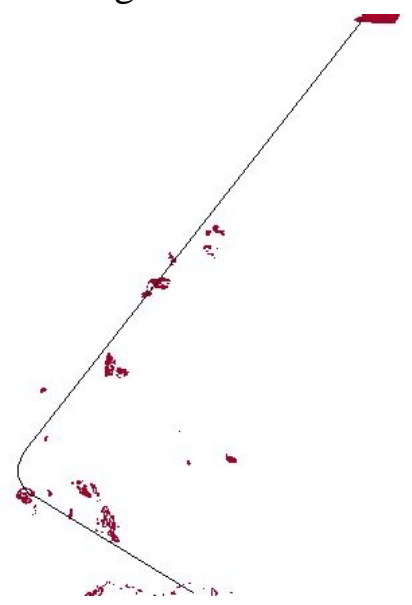

Fig.6 Cross-sea channel route selection scheme four

\section{Comparison with the existing line selection schemes}

Yueling Zhang [1] pointed out that the scheme for the tunnel route from southwest corner of the Lvshun LaoTieShan to the Penglai Fenghuotai. The way can make use of the Nanhuangcheng Island, Beihuangcheng Island, Nanchangshan Island and Beichangshan Island to build tunnel's ventilation shafts, whose main project is about 123 kilometers. Guangjie Lu [11] pointed out an all tunnel scheme, which is from the LaoTieShan to Penglai via Beichenghuang Island, Nanchenghuang Island, Daqin Island, Tuoji Island, Beichangshan Island and Nanchangshan Island. Its length is about 130 kilometers. By comparing the two schemes with the previous four schemes, we can get: 
(1)Route length from small arrives arranged in order: scheme one $<$ scheme two $<$ scheme three<scheme Yueling Zhang <scheme four<scheme Guangjie Lu.

(2) The number of routes on the island from small arrives arranged in order: scheme two<scheme Yueling Zhang <scheme one=scheme three=scheme four $<$ scheme Guangjie Lu.

(3) Thinking of the length of the six routes and the number of routes of the island, the scheme one is the relatively good scheme of the six schemes. But there are other lines in the future design and compare these kinds of schemes, it may get other results.

\section{Conclusions}

There are already a number of scholars and experts concerned about the Bohai Strait cross-sea channel project. Members of the task force have been set up to vigorously promote the study of the Bohai Strait cross-sea channel. The following conclusions can be drawn from this study:

(1)Through using the relevant knowledge of geographic information system, combined with Arc GIS software, Auto CAD software, "code for design of High Speed Railway" and the Bohai Strait cross-sea channel construction background, this paper designed the Bohai Strait cross-sea channel route scheme and got four different route schemes.

(2) Comparison of four route schemes in this paper with two route schemes of other scholars, from the length of the route and the route passing through islands the two aspects, this paper provided a reference for the construction of the sort of the Bohai Strait cross-sea channel.

\section{References}

[1] Yueling Zhang: Railway Economics Research Vol. 21 (2013), p. 12-24 (In Chinese)

[2] Bin Wang, Changning Deng, Fei Liu, in: KUAHAI ZHUMENG-BOHAI HAIXIA KUAHAI TONGDAO YANJIU XINCHENGGUO, edited by Liqun Wei and Xinhua Liu, Analysis of the impact of cross sea channel construction on Circum-Bohai container transport system, Economic science publish(2014). (In Chinese)

[3] Mengshu Wang: ENGINEERING SCIENCES, Vol. 15(2013), p. 4-9 (In Chinese)

[4] Mengshu Wang: The Earth Vol. 34(2014), p. 66-69 (In Chinese)

[5] Yuwu Sun: Northern Communications Vol. 29(2006), p. 21-23 (In Chinese)

[6] Kezhi Song, Mengshu Wang: Ludong University Journal (Natural Science Edition) Vol. 22(2006), p. 253-260 (In Chinese)

[7] Kezhi Song, Jianjun Deng, Mengshu Wang: Chinese Journal of Underground Space and Engineering Vol.4 (2007), p. 45-51 (In Chinese)

[8] Yong Zhao, Baohong Tian and Peng Li: ENGINEERING SCIENCES Vol. 15(2013), p. 39-44 (In Chinese)

[9] State Railway Administration: TB10621-2014 J1942-2014 code for design of High Speed Railway (China Railway Publishing House, Beijing 2014). (In Chinese)

[10] (American) Kang-tsung Chang, Jianfei Chen, etc.: Introduction to Geographic Information Systems (Science Press, Beijing 2016). (In Chinese)

[11] Guangjie Lu and Baohong Tian: RAILWAY STANDARD DESIGN Vol.60 (2013), p. 37-41 (In Chinese) 